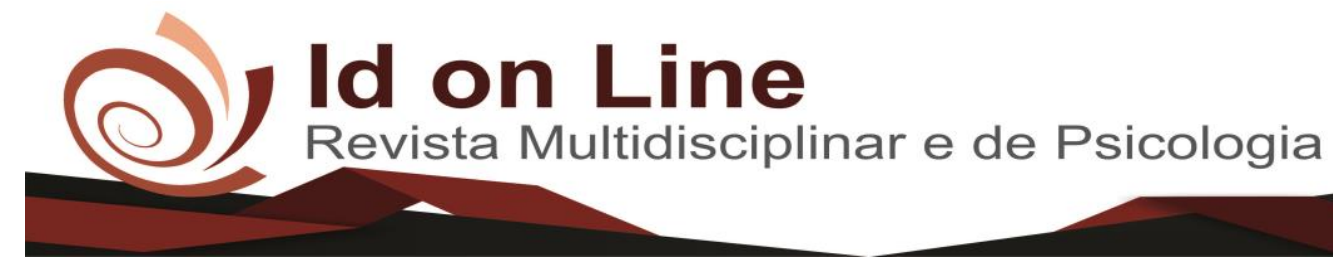

DOI: 10.14295/idonline.v14i53.2879

Artigo

\title{
Arte Resistência e Existência: A Arte Como Forma de Existência de Alunas com Deficiência Intelectual
}

Gabriela Selau Benetti ${ }^{1}$, Amanda Castro $^{2}$

\begin{abstract}
Resumo: Através dos variados recursos da arte, ela oferece um espaço para expressão de sentimentos, autoafirmação e criatividade. Surge como uma forma pela qual o aluno com deficiência intelectual possa se expressar e que sua voz seja escutada e abraçada, considerando os estigmas que carrega pela sociedade em que existe e "resiste". Por isso, buscou-se analisar como a arte propicia o reconhecimento de si e reflete o protagonismo desses alunos. A pesquisa foi realizada remotamente através de chamadas de vídeo com cinco alunas da APAE de Içara - SC ao serem questionadas sobre quem elas são e o que a arte significa para elas. Por meio de análise de conteúdo foi possível investigar através de desenhos e na interação como a arte propiciou a expressão de sentimentos, protagonismo e sociabilização. Este estudo permitiu compreender como a arte é potencializadora, que além de terapêutica, contribuiu para o desenvolvimento cognitivo e singular.
\end{abstract}

Palavras chaves: Arte; Deficiência intelectual; Psicologia.

\section{Art Resistance and Existence: Art as a Form of Existence for Students with Intellectual Disabilities}

\begin{abstract}
Through the various resources of art, it offers a space for expression of feelings, selfassertion and creativity. It appears as a way for the student with intellectual disability to express himself and for his voice to be heard and embraced, considering the stigmas he carries by the society in which he exists and "resists". Therefore, I sought to analyze how art propitiates the recognition of oneself and reflects the protagonism of these students. The research was carried out remotely through video calls with five students from APAE Içara - SC when they were asked about who they are and what art means to them. Through analysis of content it was possible to investigate through drawings and in the interaction how art propitiated the expression of feelings, protagonism and sociability. This study allowed us to understand how art is empowering, which besides being therapeutic, contributed to the cognitive and singular development.
\end{abstract}

Keywords: Art; Intellectual disability; Psychology.

\footnotetext{
${ }^{1}$ Graduação em Psicologia. Universidade do Extremo Sul Catarinense, UNESC, Brasil. gabrielaselau @ gmail.com; ${ }^{2}$ Doutora em Psicologia pela Universidade Federal de Santa Catarina. Mestre em Psicologia- UFSC. Especialista em Psicodrama pelo Centro Universitário Amparense - Unifia. Especialista em Psicologia do desenvolvimento pela Universidade de Araraquara - UNIARA. Psicóloga formada pela Universidade do Sul de Santa Catarina. Professora na Universidade do Extremo Sul Catarinense - Unesc e na Estácio de Sá. Docente no curso de formação e Especialização em Psicodrama na Escola Viver Mais Psicologia. cetica@unesc.net.
} 


\title{
Introdução
}

\section{Deficiência intelectual e problemáticas}

Conforme Bissoto (2014) até a década de 1980 a definição de deficiência intelectual era conceituada como um rebaixamento da capacidade intelectiva, assim afirmavam através de avaliações psicométricas da inteligência. Porém, segundo a autora essas medições geraram classificações sobre quem seria "educável", "treinável", "dependente" e outras.

A autora manifesta que devido a movimentos em defesa dos direitos das pessoas com deficiência, a partir de 1990, houve uma mudança no conceito:

\begin{abstract}
O modelo médico-psicológico de definição da deficiência intelectual passa a ser gradativamente mais questionado, dando espaço para outros modelos de compreensão desta, como o Modelo Social e o Biopsicossocial. No modelo social, rejeita-se a ideia de incapacidade associada à deficiência, entendendo-se que são os entraves atitudinais e ambientais, presentes no contexto sociocultural, que obstaculizam o desenvolvimento das potencialidades dos sujeitos, gerando-se daí as rotulações de "deficiente". Já o modelo biopsicossocial defende que a conceituação e definição da deficiência somente é possível considerando-se a compreensão ampla do contexto de vida, analisando-se conjuntamente as barreiras e os facilitadores às atividades existentes no ambiente e as condições de desempenho destas atividades, por parte dos sujeitos. (BISSOTO, 2014, p.4)
\end{abstract}

Com a transição apresentada anteriormente do Modelo Médico-Psicológico, a qual as pessoas com deficiências foram vistas, foi possível perceber uma humanização do conceito no Modelo Social e Biopsicossocial. De acordo com Política Nacional de Educação Especial na Perspectiva da Educação Inclusiva "considera-se pessoa com deficiência aquela que tem impedimentos de longo prazo, de natureza física, mental ou sensorial que, em interação com diversas barreiras, podem ter restringida sua participação plena e efetiva na escola e na sociedade" (BRASIL, 2008) Importante ressaltar essa lógica de efetividade na escola e sociedade como algo esperado para alunos sem deficiência intelectual, isso não afirma que o aluno com deficiência intelectual não poderá ser efetivo do seu próprio modo, poderá e muito se abraçado e instigado para tal.

$\mathrm{Na}$ argumentação de Bissoto (2014) embora o discurso de inclusão escolar e social se multipliquem, a pessoa com deficiência intelectual não tem tido oportunidade de exercer o seu protagonismo. As razões para isso podem ser que: primeiro, a concepção de que o processo de decisão é racional e complexo e não estaria ao alcance das "capacidades" da pessoa com deficiência intelectual; segundo, a superproteção dos familiares, cuidadores e profissionais devido ao medo de que as pessoas com deficiência possam ser vulneráveis podendo ser 
enganados, abusados ou explorados; terceiro, a concepção de que o deficiente intelectual teria um padrão anormal de desenvolvimento exigindo ter uma correção, controle e tutela; e por último, as próprias dificuldades que possuem relacionadas à sua deficiência intelectual, como a presença de comorbidades ou outras deficiências que podem estar associadas (BISSOTO, 2014).

Com tal característica, o ambiente em que essas pessoas se encontram, podem estar pouco estruturados socialmente para refletir seu protagonismo, e ainda é feito pouco esforço para esclarecer a pessoa com deficiência intelectual de que ela tem condições e direito de fazer escolhas, decidir-se, autodeterminar-se e de ser protagonista de sua história. Quanto mais os sujeitos refletem sobre suas escolhas e decisões, mais são considerados autônomos de si. É preciso defender a autonomia como um valor fundamental e como necessidade humana para a qualidade de vida dos sujeitos, especialmente para aqueles que são negligenciados como é o caso das pessoas com deficiência intelectual. E ainda conforme essas pessoas vivenciam e interpretam as suas próprias ações, internalizam identidades que instigam outras ações (BISSOTO, 2014). Quanto mais as pessoas com deficiência foram encorajadas na estimulação da sua autonomia, mais impulsos terão para ser quem são.

\title{
Arte e protagonismo de pessoas com deficiência intelectual
}

O autor Costa (2016, p. 7) discorre sobre a origem do termo protagonismo juvenil:

\begin{abstract}
De onde vem o termo protagonismo juvenil? Vem do grego. Proto quer dizer o primeiro, o principal. Agon significa luta. Agonista, lutador. Protagonista, literalmente, quer dizer o lutador principal. No teatro, o termo passou a designar os atores que conduzem a trama, os principais atores. O mesmo ocorrendo também com os personagens de um romance. No nosso caso, ou seja, no campo da educação, o termo protagonismo juvenil designa a atuação dos jovens como personagem principal de uma iniciativa, atividade ou projeto voltado para a solução de problemas reais. O cerne do protagonismo, portanto, é a participação ativa e construtiva do jovem na vida da escola, da comunidade ou da sociedade mais ampla.
\end{abstract}

Pensar num protagonismo das pessoas com deficiência intelectual seria refletir nessas pessoas conduzindo a trama da própria vida.

Em Mello et. al (2014) vamos encontrar o esclarecimento de que na vida de pessoas com deficiência intelectual são mantidas relações assimétricas de poder, em que as colocam como "'marionetes"' nas mãos de pessoas que se mostram bem intencionadas, mas que acabam por reproduzir práticas e representações enraizadamente preconceituosas, ignorando o protagonismo destes. 
Em vista disso, é preciso retirar a visão de que a pessoa com deficiência é incapaz. Sendo necessário abaixar o véu do preconceito e enxergar tudo aquilo que anteriormente não era visto, ou seja, enxergar claramente as potencialidades dessas pessoas. Não só temos que considerar o protagonismo da pessoa com deficiência, mas fazer com que haja formas de possibilitar esse protagonismo (MELLO et al., 2014). Sendo a arte uma delas.

Ao se referir à arte, Rosseto e Mori (2020) descrevem que ela é vista como uma das categorias do trabalho, uma forma de apropriação da realidade e uma contínua produção do mundo humano, algo que quebra o cotidiano, o momentâneo e o prático. Com isso podemos alegar que a arte tem suas variadas formas? "Quando o aluno cria com liberdade, fazendo seus desenhos e suas produções, ele levanta hipóteses e imprime sua marca na construção simbólica de sua história" (BATISTA; MANTOAN, 2016, p. 61). Segundo as autoras a arte é uma forma pela qual o sujeito pode se expressar, sendo desse modo e principalmente, na deficiência intelectual em que alguns alunos não se exprimem oralmente ou pela linguagem escrita, podem fazer isso através da arte, demonstrando capacidades desses alunos em que muitas vezes as pessoas acham que estão ocultas ou que são desacreditadas (BATISTA; MANTOAN, 2016). Assim, "A arte nesses espaços, para além do puro entretenimento, ou mesmo de uma terapêutica, pode ser pensada como uma potência capaz de contribuir nos processos de desenvolvimento cognitivo e subjetivo - de todos e de cada um. " (NEVES, 2017, p. 502) Dessa forma, podemos afirmar que há variados benefícios da arte na vida de todos.

\section{Arte Resistência e Existência}

Quando dialogamos em propiciar a arte para pessoas com deficiência, Figueira (2012) sendo seu segundo livro citado aqui, reflete sobre o objetivo de sociabilização que promove a inclusão. Através dos variados recursos da arte, ela oferece espaços para: expressão, autoafirmação, livre exploração e incentivo da criatividade. Assim, na arte, e:

[...] Por meio dela, podem-se criar espaços onde essas pessoas sejam estimuladas ao
convívio social usando, por exemplo, as possibilidades ligadas às artes plásticas. Em
escolas ou instituições que mantenham salas de artes, essas pessoas devem encontrar
a oportunidade de participar de uma situação social gratificante; compartilhando o
material com os colegas, observando o que o companheiro está fazendo ou
produzindo, conversando e ouvindo o que o colega tem a dizer, esperando a sua vez
de ser atendido e, assim, aprendendo e vivenciando a cooperação e
integração/inclusão (FIGUEIRA, 2012, p. 77).

As vivências artísticas no contexto escolar devem refletir no cotidiano dessas pessoas, onde podem desenvolver seus próprios caminhos de expressão através dos materiais, técnicas 
e conhecimento das artes. Porém, as práticas educacionais acabam favorecendo um individualismo, concedendo que a pessoa se feche nas suas próprias capacidades e circunstâncias. A arte aparece para combater esse individualismo equiparando as pessoas por iguais e compreendendo a diversidade da sociedade, ou seja, com pessoas diferentes e capacidades distintas (FIGUEIRA, 2012).

Nas palavras de Figueira (2012) há pelo menos dois possíveis caminhos em que processo educacional guia a pessoa com deficiência para a vida profissional: a Arte Comercial e o Artesanato. Se tratando da Arte Comercial ou conhecida como Pop Art, ela surgiu na década de 50 no Reino Unido, sendo uma tendência das artes plásticas, explorando componentes da cultura de massa e da sociedade de consumo. A linguagem da publicidade, quadrinhos, fotografia, ídolos são pilares para as criações designadas para a massa. No Artesanato, os próprios artesãos vendem seus produtos realizados por trabalho manual, possuindo a produção e realizando todas as etapas dela (FIGUEIRA, 2012).

Para além do que foi explicitado pelo autor, relacionando à arte e pessoa com deficiência intelectual, nos contextos de trabalho em Arte Comercial e Arte Artesanal, quero identificar e dialogar como a arte reflete no protagonismo das pessoas com deficiência intelectual, como é a visão que essas pessoas têm de si através de suas expressões artísticas. Conforme a fundamentação teórica trouxe, pensar na arte como forma de existência e resistência de pessoas com deficiência intelectual. Existência como forma de ser no mundo e resistência para os tantos estigmas que envolvem as pessoas com deficiência intelectual.

\section{Método}

As pessoas pesquisadas foram cinco alunas da APAE de Içara - Santa Catarina e que moram em Içara, indicadas pela diretora e psicóloga da escola, sendo no mínimo cinco alunos, devendo as pessoas pesquisadas e os responsáveis legais concordarem com a participação. Não houve critério de exclusão e inclusão acerca de gênero, porém as pessoas pesquisadas são do gênero feminino. Os critérios de exclusão consistiram em pessoas autistas por não estarem necessariamente relacionadas à deficiência intelectual, pessoas com deficiência intelectual que não conseguiriam compreender a proposta da pesquisa e que não teriam auxilio para realizá-la em casa visto que foi feita por vídeo chamada e pessoas surdas, por razão da pesquisadora não estar familiarizada com libras. 
A pesquisa abarcou encontros com a duração de no máximo $2 \mathrm{~h}$, para cada aluna, podendo ocorrer mais encontros, porém não houve a necessidade vista pela pesquisadora. Tais encontros ocorreram pelo aplicativo de celular Whatsapp visto que ele é comumente utilizado, o que possibilitou realizar vídeo chamadas individuais entre as alunas pesquisadas e pesquisadora. As vídeo chamadas foram gravadas em formato de vídeo e áudio, com o consentimento das alunas pesquisadas e de seus responsáveis legais. As gravações de vídeo e áudio somente foram utilizadas para fim de análise da pesquisadora. Tal método digital foi pensado devido à pandemia do COVID-19, mantendo a segurança de todos por não haver contato físico.

Nesses encontros a pesquisadora questionou as alunas sobre quem elas são e o que a arte significa para elas (Apêndice B), conforme a dificuldade em compreender a pergunta foi buscado caminhos para uma compreensão da pergunta mais perto da realidade de cada uma. Após a reflexão, poderiam realizar desenhos, fotografias e/ou qualquer forma de arte livre para que expressassem a questão proposta, houve o tempo de no máximo 1 hora e meia para a produção da atividade. Todas as cinco alunas escolheram realizar apenas desenhos enquanto dialogavam com a pesquisadora. Se durante a pesquisa ocorresse problemas na conexão da internet ou o aluno não conseguisse acessar a internet, as fotografias e/ou desenho seriam enviados por e-mail ou whatsapp, isso não ocorreu.

A coleta da pesquisa foi feita com os desenhos realizados pelas alunas. E a análise de conteúdo desse material referente ao tema, acerca do olhar que o aluno tem de si mesmo, ampliando a busca por referências bibliográficas.

Os riscos da perda de confidencialidade dos dados foi amenizado pela privacidade mantida, pois não foram divulgados os dados pessoais das alunas pesquisadas. $\mathrm{E}$ os benefícios da pesquisa consistiram em motivar o protagonismo das alunas com deficiência intelectual através da arte favorecendo o reconhecimento identitário.

\section{Resultados e Discussão}

\section{Análise de Conteúdo: Apresentação das pesquisadas}

As cinco alunas pesquisadas da APAE de Içara - Santa Catarina, tem idade entre 23 e 40 anos. A escolha dos nomes tem relação com os desenhos trazidos pelas participantes para o 
significado de arte: a imagem de flores, bem como às roupas que usavam durante a coleta de dados. Os nomes escolhidos foram: Margarida, Rosa, Flor, Tulipa e Pétala.

\section{Sobre os desenhos}

Na vídeo chamada Margarida estava com um blusão rosa com desenho de margaridas. Seu cabelo é liso, preto e comprido e tem uma franja para o lado direito. Quando questionada como ela se desenharia no papel, esboçou um sorriso aparentemente tímido. Questionada novamente se faria o desenho com o cabelo comprido e preto, assim como é, ela diz ' $E u$ desenharia eu com o cabelo curto'”. Quando uma pessoa desenha artisticamente uma imagem de si, ou seja, ela faz um autorretrato, coloca as próprias percepções na obra. O autorretrato é uma releitura da pessoa sobre si própria, a partir das suas vivências e experiências, ele nunca será exatamente a pessoa em si (MAGALHÃES, 2013). A arte proporcionará não somente o reconhecimento de si, mas também as inúmeras possibilidades que a pessoa poderá ser, testando as representações da própria imagem. O autorretrato de Margarida (Figura 1) está centralizado na folha feito apenas com lápis de escrever, apresenta o cabelo liso e curto, a cabeça redonda, usando um vestido sem detalhes na altura do joelho, mãos e pés em formato de círculos e um risco horizontal para o chão. $\mathrm{O}$ desenho mostra a representação da própria imagem sem muitos detalhes.

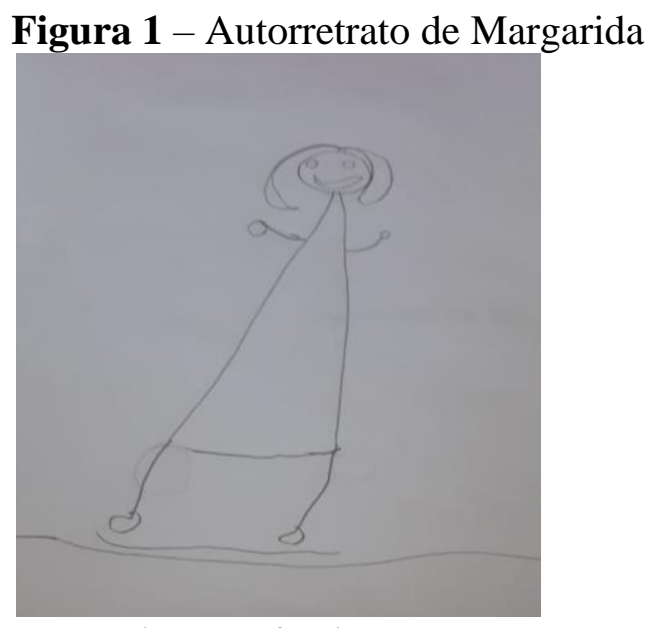

Fonte: da pesquisada.

Assim como no desenho de Margarida, a aluna Rosa retratou-se sem muitos detalhes, que no caso poderiam favorecer o reconhecimento de si. No desenho (Figura 2), colocou-se no centro da folha, o cabelo parece estar amarrado, a cabeça redonda, a boca vermelha e fez um 
vestido vermelho longo onde não aparecem os pés, os braços e mãos são grandes e de cor laranja. A escolha de colocar o autorretrato no meio da folha pode mostrar uma condição de protagonista, onde a figura principal está centralizada com maior visibilidade.

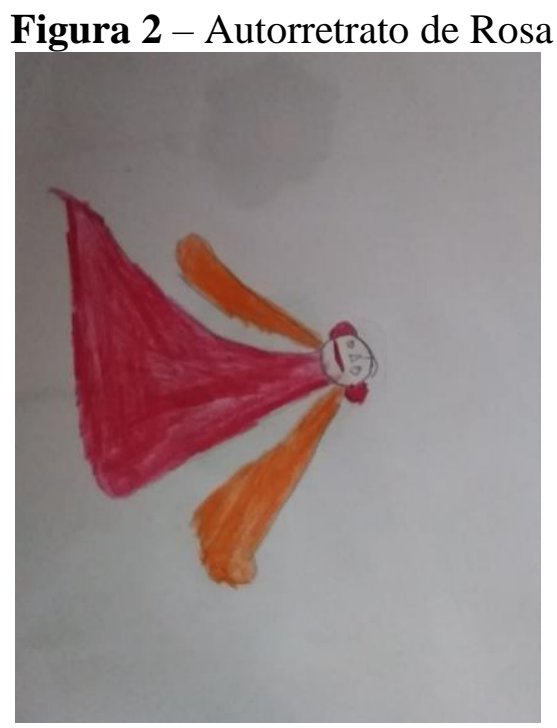

Fonte: da pesquisada.

Na vídeo chamada Rosa estava com o cabelo amarrado em coque e de cor preto, estava vestindo uma regata listrada preta e branca com o desenho de um tigre. $\mathrm{O}$ autorretrato vai além da própria imagem, através do processo criativo de pensar e elaborar a criação que se desenvolve o autoconhecimento da representação do eu (MAGALHÃES, 2013).

Quando Rosa foi questionada sobre fazer um desenho dela, cruza os braços, coça o nariz, se inclina para frente do celular e pergunta "Mas desenhar o que?". Para a pesquisada talvez não tenha sido fácil perceber que a proposta era desenhar a si mesma, pode ser por não estar habituada a essa proposta. Desse modo é relevante trazer a arte como ferramenta de autoconhecimento e não apenas como expressão do mundo. Nesse sentido, há diversas formas para as artes se associarem ao autoconhecimento, através de expressões plásticas, música, desenho e etc. A arte em si tem um impacto em nosso estado emocional e certamente altera a nossa percepção pelas coisas (QUARESMA, 2019).

$\mathrm{Na}$ segunda proposta de desenho para Rosa, sobre o que ela poderia desenhar que a lembrasse a arte, ela diz “... a gente já fez aqueles banco, não tem aqueles banco que tem na escola? "Se referindo a pintura de desenhos nos bancos da escola. Através do meio artístico é possível propor outras formas de interação com os espaços urbanos, vias que afloram novos planos de relações com esse espaço (NUNES JUNIOR; BATISTA, 2015). O diálogo com Rosa 
trouxe a arte como forma de apropriação do espaço da escola, o que pode ampliar a identidade de lugar da pesquisada. Além de ter auxiliado na socialização entre pesquisadora e pesquisada. Com isso, após Rosa ter desenhado duas flores uma do lado da outra na proposta do segundo desenho, seguiu-se o diálogo:

Pesquisadora: "Ah que bonito, e tu gosta de flor?

Rosa: Gosto, gosto de flor.

Pesquisadora: É?Eu também

Rosa: Daí eu pinto e eu bato foto.

Pesquisadora: Então tu vai pintar primeiro e depois vai me enviar foto, isso? Obrigada então, te agradeço.

Rosa: De nada. Tu é da onde?"

Rosa se inclina para frente do celular e sorri ao perguntar.

Assim aconteceu com a aluna Flor, quando foi proposto fazer o primeiro desenho, mudou de assunto e disse: "A psicóloga me falou que tu ia falar comigo, pra fazer o trabalho" apoiando a mão na cabeça e sorrindo enquanto falava, pareceu estar mais interessada em fazer daquele espaço para desenhar, um diálogo. Dessa forma,

[...] a Arte abre caminhos para a inclusão social de qualquer ser humano. Ela lapida de forma graciosa a pedra mais bruta da exclusão, ela enverga o galho mais firme do cerne. Pois, o processo da Arte é manso, suave, e intenso, ela atinge a alma do ser humano (NUNES, 2013, p.7).

Através da possibilidade de desenhar, abriu-se um espaço para a socialização. Depois de desenhar a primeira proposta de desenho, Flor disse: "Tu ia convida eu pra ir lá na escola, mas não tem como. Mas aí quando tem que fazer assim não tem problema nenhum. Fazer o que né, esse corona... A gente não pode nem sair né." $\mathrm{E}$ depois: "A gente nem sabe quando nós vai voltar também, elas não falaram. Que mais tu quer fazer?". Nesse diálogo, Flor trouxe suas inseguranças referentes ao isolamento social que a pandemia trouxe e num desenho relacionado à arte, fez uma casa com paredes de cor marrom e telhado de cor laranja, com três portas e três janelas abertas e a estrutura da casa é alta. A aluna Pétala, dias depois de ter realizado a chamada de vídeo, enviou uma foto com enfeites de bolas de natal pintados com lápis de cor, o desenho apresenta oito bolas nas cores verde, vermelho, marrom, azul, laranja, amarelo e roxo, decoradas com listras coloridas, estrelas e pontilhados, ainda ao fundo das bolas há estrelas desenhadas. Desse modo, a arte surge como forma de representação de emoções e elaboração da realidade. Assim, Pétala demonstrou no diálogo uma preocupação com o COVID-19, mas logo no desenho que representa o Natal, pode parecer haver uma elaboração do natal mesmo em tempos de pandemia. 
No processo de autoconhecimento e exteriorização de sentimentos a arteterapia se destaca. Ao conseguir transpassar os sentimentos para as formas de expressão de arte, promove-se a (re)significação da expressão escondida na pessoa e que não havia a possibilidade antes de externalizá-la (AZEVEDO et al., 2014).

Antes de iniciar a vídeo chamada com a aluna Tulipa, ela enviou a foto da sua mesa com todos os materiais de desenhos dispostos, lápis de cor, canetas, borracha, apontador e um caderno de desenho com as folhas em branco (Figura 3). Essa escolha e organização dos materiais demonstram a disponibilidade interna para a atividade. Pode ser que ao escolher e organizar o material também escolhe organizar a si mesmo. Assim,

[...] ter contato com o novo, descobrir habilidades e potenciais desconhecidos viabilizam a construção da identidade de cada pessoa. Manusear uma peça virgem, atribuir-lhe cores e forma, materializa a essência do ser que o faz, envolvendo toda sua gama de emoções e percepções. Através desse processo criativo, experiencia-se o resgate da autoestima, a consolidação da identidade e o renovar da convivência com o diverso (SOUZA; BARCELLOS, 2016, p.5).

Se colocar em contato com o desconhecido e com o novo, pode auxiliar na construção da identidade. A arte se destaca como forma de organização da identidade. Traz como um processo educativo, uma viabilidade de criação do conhecimento. Através da arte, capacidades e habilidades são aprimoradas e desenvolvidas, a concentração, autoestima, autocontrole, paciência,motricidade fina e criatividade. Assim, cria-se a situação de acolher e estimular à admiração por si próprio (SOUZA; BARCELLOS, 2016).

Figura 3 - Desenho da organização da mesa de Tulipa

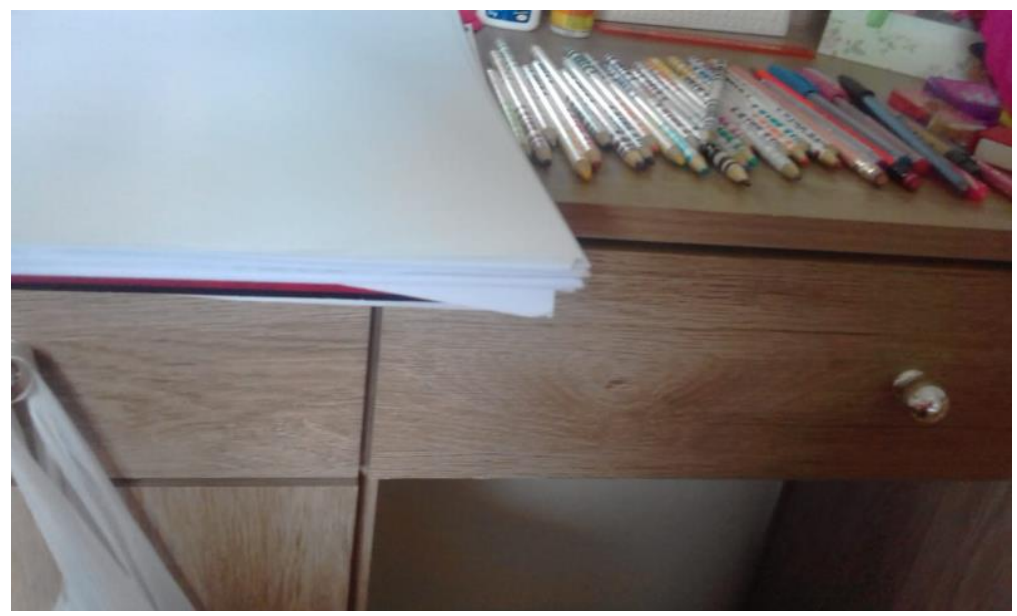

Fonte: da pesquisada.

Conversando com Tulipa sobre o que ela poderia desenhar que a remetesse à arte, ela diz que desenharia uma casa. Essa escolha da casa para representação da arte pode remeter à 
ideia de identidade, lar, aconchego e pertença em relação ao tema. Pela história, a arte tem uma importante função de expressar os sentimentos e emoções das pessoas, uma forma de traduzir a alma. Trabalhar com um processo criativo revela e inspira a pessoa a entrar em contato com um cenário de desafiar, acreditar, reconstruir, criar e expressar as suas emoções e sentimentos (AZEVEDO et al., 2014).

A aluna Pétala também se mostrou disponível internamente para realizar a atividade. Assim como Tulipa, ela também enviou uma foto dos materiais de desenho, lápis de cor, lápis de escrever, borracha, canetinhas coloridas e um caderno de desenho com a folha em branco antes de iniciarmos a chamada de vídeo.

Logo no início da conversa Pétala conta que faz artesanato, o fuxico. "Eu preciso de fazer as coisas do artesanato, eu faço fuxico, essas coisas né." "To fazendo flor. Eu fiz hoje quatro flor" Quando questionada onde aprendeu, ela diz"Adivinha? Na escola né".

Para Ribeiro (2019), através da análise de pesquisas foi possível notar que a participação de mulheres em grupos de trabalhos artesanais auxiliou na inserção das mesmas no espaço público. Pode significar não apenas com a realização do trabalho, mas sim a conquista desse espaço, significado e valor pessoal, sabendo que pela história o significado da mulher é atrelado ao homem e família, assim também significa a conquista da emancipação daquelas que foram subalternas (RIBEIRO, 2019).

Quando questionada sobre a segunda proposta de desenho, sobre o que lembra a arte, Pétala diz "O que eu gosto de fazer, que é um tipo de arte? De fazer fuxico" em seguida diz "Desenhar eu fazendo fuxico". O artesanato, no caso de Pétala o fuxico, aparece como forma de protagonismo e de manutenção da autoestima, surgindo como um reconhecimento de potência dela.

O artesanato significa uma possibilidade de geração de renda, trazendo melhorias na qualidade de vida da pessoa artesã e também como um constituinte de inclusão social, à medida que pode oferecer uma profissão. Ainda, pode promover o aumento da autoestima, de modo com que o trabalho é valorizado por quem faz e pelas pessoas no geral (BARBOSA; D’ÁVILA, 2014). 
Figura 5 - Desenho de Pétala segurando o Fuxico de Flor

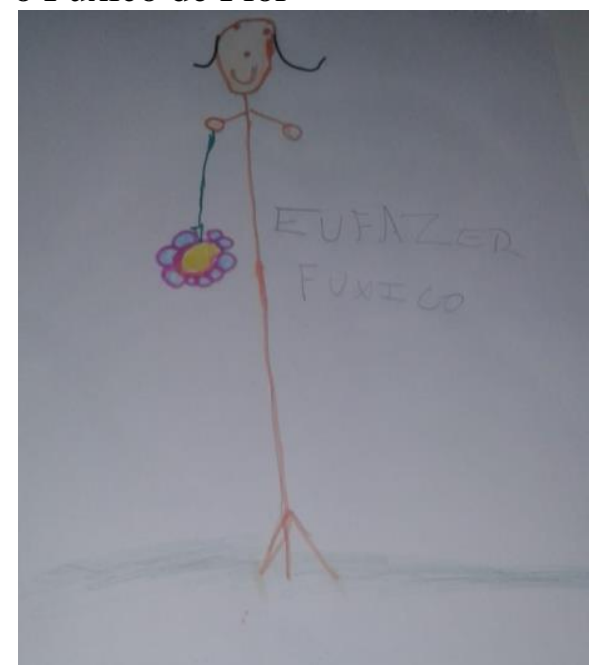

Fonte: da pesquisada.

O desenho de Pétala (Figura 5) aparece com bastantes detalhes na representação do fuxico com caule na cor verde, pétalas de cor azul com contorno rosa e o meio da flor está em amarelo. A Pétala está segurando o fuxico com a mão direita em formato de círculo, o corpo é de palito na cor bege e o cabelo preto arqueado. Os detalhes podem representar a importância da confecção e costura, como uma estratégia de reconhecimento de si. Logo, Quando Pétala é convidada a desenhar um autorretrato, ela diz "Eu não vou desenhar muito bem ta, mas desenho do meu jeito ta". Ela reconhece o próprio jeito de desenhar e fazer a sua arte. Esse reconhecimento pode implicar numa ampliação do protagonismo.

O fazer a arte inspira formas de utilizar ferramentas, organizar movimentos corporais e de refletir materiais que possibilitem levar a vida com habilidade. Essas habilidades refletem na vida do cotidiano e nas relações que a pessoa estabelece assim produzir algo material proporciona técnicas de experiências que podem beneficiar no trato com as outras pessoas (BARBOSA; D’ÁVILA, 2014). Lidar com a vida do cotidiano e com as relações com o meio social amplia o protagonismo, fazendo com que a pessoa ocupe o papel principal nas decisões de sua vida.

\section{Considerações Finais}

Este estudo buscou compreender e analisar como a arte propicia o reconhecimento de si da pessoa com deficiência intelectual, como se reflete o seu protagonismo e expressões de sentimentos. Ao longo das entrevistas realizadas por chamada de vídeo foi possível observar a 
receptividade das alunas em participar da pesquisa, tanto com os materiais dispostos sobre a mesa, quanto para conversar enquanto desenhavam. Os assuntos foram variados: expressaram suas angustias referente ao COVID-19, compartilhamento de trabalho manual com arte, reflexões sobre o que desenhar e interesse em conhecer a pesquisadora. Este estudo contribuiu para compreender o papel da arte no trabalho com pessoas com deficiência intelectual, alvos de grande capacitismo por parte de uma sociedade que os julga incapazes de cuidar da própria vida, ou quando tais pessoas precisam de mais auxílio são ainda mais estigmatizadas. Considera-se necessário ampliar as pesquisas nesse campo, com maior número de participantes e tendo em vista quais as formas de arte podem contribuir de forma mais eficaz para o protagonismo da pessoa com deficiência. Por fim, inicialmente teve-se a impressão de que a forma de pesquisa remota seria uma limitação para a pesquisa, por ter a realização de desenhos e outras formas artísticas, mas após a finalização do trabalho compreende-se que esse novo formato trouxe uma forma única e diferente para a realização da arte, que trouxe um caráter maior de intimidade, por se delinear na casa dos participantes.

\section{Referências}

AZEVEDO, Elisângela Braga de et al. ARTETERAPIA COMO PROMOTORA DA QUALIDADE DE VIDA E INCLUSÃO SOCIAL DE PROFISSIONAIS E USUÁRIOS. Revista da Universidade Vale do Rio Verde, Três Corações, v. 12, n. 2, p. 167176, ago./dez. 2014. Universidade Vale do Rio Verde (UninCor). http://dx.doi.org/10.5892/ruvrd.v12i2.1422. Disponível em: http://periodicos.unincor.br/index.php/revistaunincor/article/view/1422. Acesso em: 25 nov. 2020.

BARBOSA, Vera Lucia; D'ÁVILA, Maria Inácia. Mulheres e Artesanato: um 'ofício feminino': no povoado do bichinho/prados-mg. Revista Ártemis, João Pessoa, v. 17, n. 1, p. 141-152, jan./jul. 2014. Disponível em: https://search.proquest.com/openview/e9f7feb4a3cda56dad55b352b11f39df/1?pqorigsite $=$ gscholar \&cbl=4708196. Acesso em: 25 nov. 2020.

BATISTA, C.A.M; MANTOAN, M.T.E. Educação inclusiva: atendimento educacional especializado para a deficiência mental. 2. ed. Brasília, DF: MEC, SEESP, 2006. 68p. Disponível em: <http://portal.mec.gov.br/seesp/arquivos/pdf/defmental.pdf>. Acesso em: 15 de ago de 2020.

BISSOTO, Maria Luisa. Deficiência intelectual e processos de tomada de decisão: estamos enfrentando o desafio de educar para a autonomia?. Educação Unisinos, São Paulo, v. 18, n. 1, p. 3-12, 24 nov. 2014. UNISINOS - Universidade do Vale do Rio Dos Sinos. http://dx.doi.org/10.4013/edu.2014.181.01.

Disponível em: 
http://www.revistas.unisinos.br/index.php/educacao/article/view/1917. Acesso em: 17 ago. 2020.

BRASIL. Secretaria de Educação Especial. Política Nacional de Educação Especial na Perspectiva da Educação Inclusiva. Brasília, MEC/SEESP, 2008. 19 p. Disponível em: <http://portal.mec.gov.br/arquivos/pdf/politicaeducespecial.pdf>. Acesso em: 15 ago. 2020.

COSTA. Antonio Carlos Gomes da. Protagonismo Juvenil: O que é e como praticá-lo. Instituto Aliança. Belo Horizonte, 2016. 11 p. Disponível em: <http://www.institutoalianca.org.br/Protagonismo_Juvenil.pdf> . Acesso em 27 jun. 2020.

FIGUEIRA, Emílio. A Pessoa Com Deficiência Dialogando Com A Arte: dos fatos históricos à educação escolar, rumo ao mercado de trabalho. São Paulo: Edição ao Autor: Agbook, 2012. 100 p. Disponível em: https://pt.scribd.com/book/421351238/Psicologia-Da-Arte. Acesso em: 27 out. 2020.

MAGALHÃES, Alice Maria Silva. A mediação do professor de artes em oficina de autorretrato aplicada ao ensino especial. 2013. 33 f., il. Trabalho de Conclusão de Curso (Licenciatura em Artes Plásticas)—Universidade de Brasília, Brasília, 2013.

MELLO, André da Silva; SANTOS, Wagner dos; RODRIGUES, Laís Albuquerque; SANTOS, Renata de Souza. O PROTAGONISMO DE PESSOAS COM DEFICIÊNCIA INTELECTUAL NO PROCESSO DE ENSINO-APRENDIZAGEM DA CAPOEIRA.Pensar A Prática, Goiânia, v. 17, n. 1, p. 214-127, 10 mar. 2014. Disponível em: https://www.revistas.ufg.br/fef/article/view/23706. Acesso em: 28 out. 2020.

NEVES, Libéria Rodrigues. Contribuições da Arte ao Atendimento Educacional Especializado e à Inclusão Escolar. Revista Brasileira de Educação Especial, Marília, v. 23, n. 4, p. 489-504, dez. 2017. Disponível em: https://www.scielo.br/scielo.php?script=sci_arttext\&pid=S141365382017000400489\&lng=pt\&nrm=iso. Acesso em: 15 out. 2020.

NUNES, Maria José. Arte como meio de socialização e inclusão do indivíduo. Os Desafios da Escola Pública Paranaense na Perspectiva do Professor PDE: Produções DidáticoPedagógicas, Jacarezinho, v. 2, p. 1-30, 2013. Disponível em: http://www.diaadiaeducacao.pr.gov.br/portals/cadernospde/pdebusca/producoes_pde/2013/20 13_uenp_edespecial_pdp_maria_jose_nunes.pdf. Acesso em: 24 nov. 2020.

NUNES JUNIOR, Paulo Cezar; BATISTA, Janir Coutinho. FICA na rua: arte, cultura e poéticas de apropriação de espaço urbano. Revista Rua, Campinas, v. 21, n. 1, p. 21-32, 2 jul. 2015. Universidade Estadual de Campinas. http://dx.doi.org/10.20396/rua.v21i1.8637516. Disponível

em: https://periodicos.sbu.unicamp.br/ojs/index.php/rua/article/view/8637516/5212. Acesso em: 24 nov. 2020.

QUARESMA, Marta Sofia Pereira.Desenho e Colagens - Uma experiência de autoconhecimento: relatório da prática de ensino supervisionada. 2019. 140 f. Dissertação (Mestrado) - Curso de Mestrado em Ensino de Artes Visuais, Instituto de Educação, Universidade de Lisboa, Lisboa, 2019. Cap. 2. Disponível em: https://repositorio.ul.pt/handle/10451/41981. Acesso em: 24 nov. 2020. 
RIBEIRO, Débora Inácia. Trabalho Artesanal e Autenticidade do Ser: um percurso em martinheidegger. Curitiba: Appris, 2019. 141 p. Disponível em: https://pt.scribd.com/book/448059327/Trabalho-Artesanal-e-Autenticidade-do-Ser-UmPercurso-em-Martin-Heidegger. Acesso em: 25 nov. 2020.

SOUZA, Beatriz Alice Kullmann de; BARCELLOS, Eliana Cristina Caporale. A BUSCA PELA IDENTIDADE E O DESPERTAR DA AUTOESTIMA ATRAVÉS DA ARTE: Uma vivência entre adolescentes em situação de vulnerabilidade social. In: CONGRESSO LATINOAMERICANO DE GÊNERO E RELIGIÃO, 4., 2016, São Leopoldo. Anais do VI Congresso Latino-americano de gênero e religião. São Leopoldo: Est, 2016. v. 4, p. 5-13. Disponível em: http://anais.est.edu.br/index.php/genero/article/view/605. Acesso em: 25 nov. 2020.

\section{Como citar este artigo (Formato ABNT):}

BENETTI, Gabriela Selau ; CASTRO, Amanda. Arte Resistência e Existência: A Arte Como Forma de Existência de Alunas com Deficiência Intelectual. Id on Line Rev.Mult. Psic., Dezembro/2020, vol.14, n.53, p. 619-633. ISSN: 1981-1179.

Recebido: $14 / 12 / 2020$;

Aceito: $17 / 12 / 2020$. 